\title{
Thought on Product Design Teaching Reform of Colleges in the New Period
}

\author{
Xue Gao \\ School of Art and Design \\ Sias International University \\ Zhengzhou, China
}

\begin{abstract}
Going with the time and social development, current product design has taken on a prominent change. Colleges are main places for cultivating talents of product design, in order to make talents meet the change and realize their value in the changes and development, the only way is to conduct reforms on the teaching from top to bottom according to the needs of actual situations. This article analyzes the product teaching reform in colleges in the new period on the basis of teaching practice, and represents relevant suggestions.
\end{abstract}

Keywords—new period; product design teaching; thinking of reform

\section{INTRODUCTION}

Goal goes before actions, once a teaching goal is set up, all teaching activities should be carried out aiming at the goal. As for the product design teaching, the first point that we should make sure of shall be what the talents that we will train are, or what kinds of abilities the talents trained should have. Seen from the definition of product design, the product design refers to a course where some goal or need of the people is converted into a physical form or tool through lines, symbols, colors and so on, or spoken easily, a product is designed from shape, color and the like, which can not only show the product features but so reflect personalities of the designer, satisfying the people in aesthetics and utility. Three key points can be found in the definition, namely a product designer shall be quipped with professional and comprehensive theoretical knowledge as well as real design capabilities. Compared to the current teaching, professional theoretical knowledge can be taught according to the syllabus and experience that teachers own. Yet students are still poor in comprehensive knowledge and real design ability, most are seriously affected in employment and individual development due to the lack of abundant comprehensive knowledge and adequate practices.

\section{SET A NEW TEACHING GOAL}

Colleges shall have the original teaching goals adjusted thoroughly, and what the colleges cultivate are not theoretical talents who only know the product design knowledge, and an excellent graduate of product design major shall have not only solid theoretical foundation but also thick cultural accomplishment and solid skills in practice, after graduation, such students may become a quality designer who can be devoted to the creativity immediately. So the course setting shall be renovated properly with the students' abilities in practice improved, through the construction of training bases for the colleges and introduction of more teaching projects, the students will be trained in practice so as to achieve the seamless connection between graduation and employment.

Therefore, the re-setting up of teaching goals is closely related to the time, society and the requirements to talents, and the colleges and teachers are required to follow the trend and cultivate talents who actually meet the need of the time, society and industrial development.

\section{AdJust Traditional COURSE StRUCTURE}

The product design is an integration of multiple disciplines, which get involved in all kinds of knowledge such as material, technique, production, need, consumption, aesthetics, management, society, economics and culture. Therefore, the product design major must follow characteristics of the discipline, based on the professional public teaching, it needs to set up professional basic required courses, professional basic elective courses, professional required courses and professional elective courses, professional practice course. According to the terms, set the product design course and reduce the proportion of public courses as much as possible, increase the proportion of professional basic courses and professional courses so that the students will complete the study of the professional basic knowledge courses in the first academic year. The first three terms will be designed to improve the students' theoretical skills and cultural accomplishment, and the fourth term will start the professional course teaching, according to majors, integrate the class hour setting of professional required courses and make the students get professional knowledge and skills, in the meantime, professional practical courses can be a bridge for all disciplines, showing the characteristics of product design major. In the course of teaching, introduce the interdisciplinary and comprehensive design trainings to the teaching of professional courses, with the knowledge and skills used such as material forming process, bionic shape design, ergonomics, mechanical design foundation, design psychology and so on, it needs to stress the product structure design, shape design, material selection, target users analysis so as to improve the students' comprehensive capabilities of using the course knowledge in the whole design. 


\section{AdOPT NeW TEACHING ModeS}

In the traditional product design teaching, generally teachers make lectures to which, students listen, after completion of the lectures, teachers are thought to have completed the teaching tasks, which fail to show characteristics of the discipline--product design, as a result, the talents trained are all poor in the actual design ability. So the teaching mode should be renovated, project teaching method is a well going mode which is widely praised for the design course teaching, and it has achieved the optimal combination of theoretical knowledge and design ability. Spoken specifically, according to the development trend and actual needs of product design, teachers may decide the project tasks for design, if possible, just arrange more projects for students to select from. In the meantime, select similar and excellent design works and explain them to students, showing relevant design philosophy, conceptions, methods and features so as to indicate the basic direction. Considering the actual abilities of students, follow the mode of design studio and individual wills of students, set up several design groups, draw up plans and designate persons responsible. The group director will create a project design proposal, including product design information and division of group members. With the project design proposal agreed by teachers, it needs to start specific design. During the course, teachers just act as instructors, controlling over the situation rather every aspect so as to free the students. After completion of the design, multiple evaluation methods can be used such as self evaluation, group-to-group evaluation, marketing evaluation and so on, finally teachers will make a summary. In addition to full agreements with advantages of the works, the defects shall be also exposed and some excellent works can be recommended for display and public release, bringing the students concerned senses of achievements. The project teaching method succeeds in achieving the close combination of theories and practice, and the design course is just to carry out the design plans, and the whole course experience is very necessary for the students, besides, the design group also test the students' abilities in cooperation, which can be said a great support to the current teaching system.

\section{StRESS TO TRAIN THE INNOVATIVE THOUGHTS OF STUDENTS}

Innovation is the soul of design and the most precious thought. The product design teaching in colleges, seen whether from students' ages or professional learning stages, is the optimal stage to cultivate their innovative thoughts, to learn to innovate, dare to innovate and get used to innovation will bring important impact on the development of their whole lives. Specifically, the cultivation of innovative thoughts shall contain four points as follows, first of all, to train the fluency of innovative thought, it means that there shall be design schemes as more as possible with a short time, for example, teachers give a design object, and students shall make schemes within the given time. No attentions shall be paid to the good or bad or details for now, what teachers want is quantity and speed so as to stimulate students' imagination and connection, which will be basis for innovative thought. Second, we should train the flexibility of innovative thought. The flexibility means that according to changes of conditions, the students can change flexibly from one thought to another, good at observing and solving problems from multiple angles and directions. Especially nowadays, humanized products are wide advocated and designers should start with more thoughts and satisfy the people as possibly as they can. So students should open their thoughts without hesitation, in pursuit of different answers. Third, to train the originality of innovative thought, it refers to an ability to break through the routine and dare to innovate, and it is a further step for innovative thought. Take the scissors design as an example, generally the innovation is shown on the appearance of the scissors, by contrast, Japanese product designers create a safe scissors, with two springs installed, the user may use the scissors easily at any angle. This is an original innovation, accordingly during the teaching, students shall be encouraged to break through traditional habits or thoughts, adopting reverse thinking and divergent thinking, able to doubt and criticize so as to get an inspiration of originality. Fourth, to train the integration of innovative thought, it refers to a summary and collection. Generally innovative thought comes before you know it, however, it is complicated, needing processing by the designer. According to the cognitive rules "divergent-converge - re-divergent-re-converge" and "perceptual knowledge--conceptual knowledge-practice", students can be led to train the convergent thinking, summary and deduction so as to achieve the innovative thought really and feel the value and significance of innovation.

\section{CONCLUSION}

As a discipline of art design category, the product design has distinct characteristics of its own, namely the product design is closely related to the society, time and culture, varying with them. It raises a specific requirements to the product design teaching in colleges-going with the time, therefore, in the face of such as relatively outdated teaching system, it needs to review it in all aspects, keeping what is useful and rejecting what is useless, and launch a reform from top to bottom, based on it, the product designers hold the latest and most advanced whether in design thought or skills so as to truly excel in skills and use what they have learned. No doubt, the renovation of a discipline teaching system cannot be achieved in a short time, it needs the joint efforts of educational authorities, colleges and teachers. This article makes macroscopic analysis of the direction and measures for the renovation, expecting to attract more valuable contributions and more eyeballs to it, and contribute what we can to the development of product design teaching in colleges.

\section{REFERENCES}

[1] Li Jun, Rethinking of Product Design Teaching[J]. Art Education, 2011(01)

[2] Xu Ping, Zhang Yong, Thought of Product Design Course in the Teaching of Industrial Design Major [J].Design Aft (Journal of Shandong University of Art \& Design). 2009(01)

[3] Wei Rong, Research and Discussion on Teaching of Product Design Cases [J]. Market Modernization, 2009(08)

[4] Jin Chengyu, Practice of Product Design Teaching [J]. China Science and Technology Information, 2009(10). 